\title{
Resíduo proveniente do beneficiamento do feijão (Phaseolus vulgaris L.) em rações para vacas em lactação: consumo, digestibilidade, produção e composição do leite e eficiência de alimentação ${ }^{1}$
}

\author{
André Luiz Rodrigues Magalhães ${ }^{2 *}$, Karina Zorzi², Augusto César de Queiroz ${ }^{3}$, Renius Mello², \\ Edenio Detmann ${ }^{3}$, José Carlos Pereira ${ }^{3}$
}

1 Parte da tese de Doutorado do primeiro autor, DZO/UFV.
2 Programa de Pós-graduação em Zootecnia - UFV - Viçosa, MG
${ }^{3}$ Departamento de Zootecnia da UFV. Bolsista do CNPq.

RESUMO - Este trabalho foi conduzido com o objetivo de avaliar o efeito da substituição do farelo de soja pelo resíduo de feijão comum (Phaseolus vulgaris L.) em rações para vacas em lactação sobre as seguintes variáveis: consumos e digestibilidades totais aparentes dos nutrientes, produção e composição do leite e eficiência alimentar. Foram utilizadas 12 vacas da raça holandesa, distribuídas em três quadrados latinos $4 \times 4$, balanceados. Os animais receberam rações completas ofertadas ad libitum, contendo 0; 13; 26 e 39\% de resíduo de feijão cru no concentrado, em substituição ao farelo de soja. Os consumos de matéria seca (MS), matéria orgânica (MO), carboidratos não-fibrosos (CNF) e de nutrientes digestíveis totais (NDT) diminuíram linearmente com o aumento dos níveis de feijão no concentrado. Os consumos de fibra em detergente neutro (FDN) e de fibra em detergente neutro indigestível (FDNi) não foram afetados pelas dietas e os consumos de proteína bruta (PB) e extrato etéreo (EE) apresentaram comportamento cúbico. Os coeficientes de digestibilidades (CD) de MS, MO, EE e FDN não foram afetados pelas dietas, enquanto os de PB e CNF apresentaram comportamento linear decrescente e crescente, respectivamente. A produção e a composição do leite (gordura, proteína, lactose, extratos secos desengordurado e total), quando expressas em kg/dia, apresentaram redução linear para os níveis crescentes de substituição. Não houve diferença entre os tratamentos para as eficiências de alimentação. A inclusão do resíduo de feijão às dietas ocasionou redução no desempenho dos animais.

Palavras-chave: alimentação, resíduo agroindustrial, sub-produto

\section{Residue from common bean (Phaseolus vulgaris L.) processing in the rations for milking cows: intake, digestibility, milk production and composition and feeding efficiency}

\footnotetext{
ABSTRACT - This work was carried out with the objective to evaluate the effect of replacement of soybean meal by common bean (Phaseolus vulgaris L.) residue in rations for milking cows on the following variables: intakes and total apparent digestibilities of nutrients, milk production and composition and feeding efficiency. Twelve Holstein cows were randomly assigned to three $4 \times 4$ balanced latin square design. The animals was fed ad libitum total mixed rations, which contained $0 ; 13 ; 26$ and 39\% of raw common bean residue in the concentrate, in substitution of soybean meal. Dry matter $(\mathrm{DM})$, organic matter $(\mathrm{OM})$, non fiber carbohydrates (NFC) and total digestible nutrients intakes were linear depressed by the increasing levels of common bean residue in the concentrate. Neutral detergent fiber (NDF) and indigestible neutral detergent fiber (iNDF) intakes were not affected by the diets and crude protein (CP) and ether extract (EE) intakes presented cubic behavior. The digestibility coefficients (DC) of DM, OM, EE and NDF were not affected by the diets while DC of $\mathrm{CP}$ and NFC presented linear decreasing and increasing behavior, respectively. Milk production and composition (fat, protein, lactose, non fat and total dry extracts), as expressed in $\mathrm{kg} /$ day, presented linear decreasing for the increasing levels of substitution. No difference was observed for feeding efficiencies among diets. The inclusion of common bean residue in the diets prejudiced the performance of the animals.
}

Key Words: agro industry residue, by product, feeding

Este artigo foi recebido em 9/11/2006 e aprovado em 4/9/2007. 


\section{Introdução}

Os subprodutos e resíduos oriundos do beneficiamento e/ou processamento de grãos apresentam-se como alternativa promissora à redução dos custos com alimentação do rebanho leiteiro. A utilização racional desses produtos depende, entre outros fatores, de suas características nutritivas (Pereira, 2000). Dentre estes, destaca-se o resíduo do beneficiamento do feijão comum (Phaseolus vulgaris L.), por apresentar disponibilidades regionais consideráveis, visto que o cultivo do feijoeiro tem ocorrido em todos os estados da federação (CONAB, 2005). Entretanto, para que se possa incorporá-lo em rações para ruminantes, fazem-se necessários sua caracterização, o conhecimento prévio da sua composição bromatológica, a aceitabilidade pelos animais, o conseqüente desempenho e a eficiência de conversão alimentar.

Nunes (1998) caracterizou o resíduo de feijão como um produto de baixa palatabilidade e digestibilidade que apresentou as seguintes recomendações: inclusão de até $15 \%$ e de 20 a $25 \%$ em concentrados destinados a bovinos e ovinos em engorda, respectivamente, não sendo relatada nenhuma indicação para vacas em lactação. Em vacas leiteiras, este fato merece apreço considerável, visto que essas são as unidades produtivas geradoras de receitas dentro do sistema de produção de leite.

Segundo recomendações do DPI (2003), o resíduo de feijão (navy bean) deve ser incluído em 20 e 10\% em dietas para gado de leite e corte, respectivamente, níveis em que a lectina seria desnaturada no rúmen. Destacou-se ainda que níveis maiores de oferta poderiam predispor ao aparecimento de acidose subclínica. Entretanto, Moss (2005) afirmou que a lectina presente nos grãos de leguminosas não é degradada no rúmen. $\mathrm{O}$ autor relatou também que o resíduo de feijão, em baixos níveis de oferta e por curtos períodos, pode não causar sintomas de toxicidade em bovinos, embora possa haver redução na conversão alimentar, e que novilhos apresentaram anticorpos específicos para lectinas, indicando efeitos adversos da oferta do resíduo de feijão.

Quantidades moderadas de grãos de leguminosas (até $1 \mathrm{~kg} / \mathrm{vaca} /$ dia) e níveis maiores para grãos com baixa toxicidade ( 2 a $3 \mathrm{~kg} / \mathrm{vaca} / \mathrm{dia}$ ) durante curtos períodos foram indicados por Moss (2005), que relatou ainda que, para ruminantes, os efeitos do fornecimento de grãos com maiores níveis de fatores anti-nutricionais ou por longos períodos sobre a eficiência alimentar são incertos.

Partindo-se da premissa de que os sistemas de produção de leite nos quais se têm utilizado ingredientes alterna- tivos para o preparo de rações podem apresentar custos de alimentação mais compatíveis com a atual realidade do setor, objetivou-se avaliar a substituição do farelo de soja pelo resíduo de feijão comum, em dietas para vacas lactantes, sobre as seguintes variáveis: consumo, digestibilidades totais aparentes dos nutrientes, produção e composição do leite e eficiência de alimentação.

\section{Material e Métodos}

Este trabalho foi conduzido na Unidade de Ensino e Pesquisa em Gado de Leite (UEPE-GL), do Departamento de Zootecnia da Universidade Federal de Viçosa (UFV), ViçosaMG. Doze vacas da raça holandesa, puras e mestiças, com potencial de produção de $6.000 \mathrm{~kg}$ de leite por lactação, foram distribuídas em três quadrados latinos $4 \times 4$, organizados de acordo com o período de lactação, que foi, em média, de 77, 127 e 87 dias para o primeiro, segundo e terceiro quadrados latinos, respectivamente, no início do experimento. Trinta dias antes do parto, as vacas foram manejadas para apresentar condição corporal ao parto de 3,5, na escala de 1 a 5 (Ferreira \& Torres, 1993).

O experimento teve duração de 60 dias e foi dividido em quatro períodos de 15 dias cada, sendo os oito primeiros destinados à adaptação dos animais às dietas e os demais para coleta de amostras. No início do experimento, as vacas foram transferidas para baias individuais e a alimentação foi fornecida duas vezes ao dia, às 8 e 16 h, logo após as ordenhas. Os animais receberam rações completas ad libitum na proporção de 60:40 volumoso:concentrado, contendo $0 ; 13 ; 26$ e 39\% de resíduo de feijão cru no concentrado, em substituição ao farelo de soja. Esses níveis corresponderam à inclusão de 0; 5,2; 10,4 e 15,6\%, respectivamente, de resíduo na dieta total, o que representou os seguintes níveis médios de oferta diária de $0 ; 1,82$; 3,45 e 4,84 g/kg PV. O resíduo de feijão foi constituído de grãos avariados dos tipos: inteiros (amassados, enrugados, manchados, despeliculados e outros), partidos (bandinhas sadias) ou quebrados (pedaços sadios) da mistura das cultivares carioca, preto e vermelho, não havendo predomínio de determinado cultivar, em mistura com impurezas e matérias estranhas.

O volumoso utilizado foi a silagem de milho e os alimentos concentrados utilizados no balanceamento das dietas foram: fubá de milho, farelo de soja, resíduo de feijão, uréia pecuária, fosfato bicálcico, calcário, sal comum e premix mineral (Tabela 1). A composição nutricional dos alimentos utilizados encontra-se na Tabela 2. As dietas (Tabela 3) foram formuladas de acordo com o NRC (1989), objetivando-se 
Tabela 1 - Composição dos ingredientes nas dietas experimentais $(\% \mathrm{MS})$

\begin{tabular}{lcccc}
\hline & \multicolumn{4}{c}{ Nível de resíduo de feijão (\%) } \\
\cline { 2 - 5 } Ingrediente (\%) & 0 & 13 & 26 & 39 \\
\hline Milho & 25,29 & 22,65 & 19,68 & 16,72 \\
Farelo de soja & 12,90 & 10,32 & 7,92 & 5,57 \\
Resíduo de feijão & - & 5,20 & 10,40 & 15,60 \\
Uréia & 0,40 & 0,40 & 0,40 & 0,40 \\
Fosfato bicálcico & 0,34 & 0,34 & 0,35 & 0,36 \\
Calcário & 0,67 & 0,69 & 0,85 & 0,95 \\
Sal comum & 0,40 & 0,40 & 0,40 & 0,40 \\
Premix mineral & 0,008 & 0,008 & 0,008 & 0,008 \\
Silagem de milho & 60,00 & 60,00 & 60,00 & 60,00 \\
\hline
\end{tabular}

1 Mistura uréia:sulfato de amônio, na proporção de 9:1.

que as mesmas fossem isonitrogenadas e com o mesmo teor de nitrogênio não-protéico (NNP).

O consumo de alimentos foi monitorado diariamente para que houvesse sobras de alimentos de $10 \%$, com base na MS, as quais foram retiradas dos cochos duas vezes ao dia. As amostragens da silagem de milho e das sobras foram feitas diariamente nos sete últimos dias de cada período experimental, enquanto os concentrados e o resíduo de feijão foram amostrados para cada lote misturado na fábrica de ração.

O preparo das amostras dos alimentos, sobras e fezes e as análises de MS, MO, PB, EE, FDN, fibra em detergente neutro corrigida para cinzas e proteína (FDNcp), fibra em detergente ácido (FDA), nitrogênio insolúvel em detergente neutro (NIDN), nitrogênio insolúvel em detergente ácido (NIDA), lignina detergente ácido e minerais foram feitas segundo Silva \& Queiroz (2002). O NNP das dietas foi determinado conforme técnica descrita por Licitra et al. (1996) e o teor de amido do resíduo de feijão e do milho, segundo AOAC (1995), modificado por Walter et al. (2005). A atividade ureática do resíduo de feijão foi determinada conforme SINDIRAÇÕES (1998).

Os carboidratos não-fibrosos (CNF) da silagem de milho e das dietas foram calculados como: $\mathrm{CNF}(\%)=100$ (\% FDNcp + \% PB + \% EE + \% cinzas) e os nutrientes digestíveis totais (NDT) das dietas, como: NDT $=$ PBD + 2,25 x EED + CNFD + FDND, de acordo com Weiss (1999), em que: $\mathrm{PBD}=$ proteína bruta digestível; $\mathrm{EED}=$ extrato etéreo digestível; CNFD = carboidratos não fibrosos digestíveis; e FDND = fibra em detergente neutro digestível. Devido à presença de uréia nos concentrados, os CNF destes foram calculados como proposto por Hall (2000): $\mathrm{CNF}=100-[(\% \mathrm{~PB}-\%$ PB derivada da uréia $+\%$ de uréia $)$ $+\%$ FDNcp + \% EE + \% cinzas].

As vacas foram ordenhadas mecanicamente duas vezes ao dia, perfazendo-se o registro diário da produção
Tabela 2 - Composição nutricional das rações concentradas, da silagem de milho e do resíduo de feijão

\begin{tabular}{|c|c|c|c|c|c|c|}
\hline \multirow[b]{2}{*}{ Nutriente } & \multicolumn{4}{|c|}{$\begin{array}{c}\text { Ração } \\
\text { concentrada }{ }^{4}\end{array}$} & \multirow[t]{2}{*}{$\begin{array}{l}\text { Silagem } \\
\text { de milho }\end{array}$} & \multirow[t]{2}{*}{$\begin{array}{l}\text { Resíduo } \\
\text { de feijão }{ }^{5}\end{array}$} \\
\hline & 0 & 13 & 26 & 39 & & \\
\hline MS (\%) & 87,11 & 87,46 & 87,12 & 87,08 & 28,21 & 86,88 \\
\hline $\mathrm{MM}^{1}$ & 6,21 & 6,25 & 7,32 & 7,87 & 5,47 & 5,30 \\
\hline $\mathrm{MO}^{1}$ & 93,79 & 93,75 & 92,68 & 92,13 & 94,53 & 94,70 \\
\hline $\mathrm{PB}^{1}$ & 23,67 & 23,82 & 22,87 & 23,09 & 5,41 & 23,12 \\
\hline $\mathrm{NNP}^{2}$ & 22,05 & 23,23 & 21,11 & 23,51 & 34,99 & 21,47 \\
\hline $\mathrm{NIDN}^{2}$ & 12,97 & 9,88 & 10,41 & 10,90 & 22,88 & 18,75 \\
\hline NIDA $^{2}$ & 8,84 & 8,74 & 8,56 & 8,65 & 12,47 & 12,64 \\
\hline $\mathrm{EE}^{1}$ & 4,6 & 2,91 & 2,89 & 2,62 & 2,44 & 1,67 \\
\hline $\mathrm{FDN}^{1}$ & 13,53 & 14,18 & 14,44 & 14,92 & 62,85 & 16,53 \\
\hline $\mathrm{FDN}_{\mathrm{cp}}{ }^{1}$ & 10,45 & 11,81 & 12,04 & 12,39 & 60,17 & 13,80 \\
\hline $\mathrm{FDN}_{\mathrm{i}}{ }^{1}$ & 1,23 & 1,54 & 1,82 & 2,50 & 21,86 & 2,92 \\
\hline $\mathrm{CNF}^{1}$ & 56,88 & 57,02 & 56,69 & 55,84 & 26,51 & 56,11 \\
\hline Amido 1,3 & - & - & - & - & - & 34,73 \\
\hline $\mathrm{FDA}^{1}$ & 5,21 & 5,45 & 5,76 & 6,45 & 35,57 & 10,37 \\
\hline Lignina $^{1}$ & 1,15 & 1,47 & 1,79 & 1,77 & 4,72 & 1,15 \\
\hline
\end{tabular}

$1 \%$ na matéria seca.

$2 \%$ do nitrogênio total.

3 O milho utilizado no preparo das rações concentradas contém $69,12 \%$ de amido.

${ }^{4}$ Níveis de resíduo de feijão nos concentrados, na base da matéria seca (\%).

${ }^{5}$ Atividade ureática média foi de 0,04 unidades de $\mathrm{pH}$.

Tabela 3 - Composição nutricional das dietas experimentais

\begin{tabular}{lcccc}
\hline & \multicolumn{4}{c}{ Dieta $^{3}$} \\
\cline { 2 - 5 } Item & 0 & 5,2 & 10,4 & 15,6 \\
\hline MS (\%) & 51,77 & 51,91 & 51,77 & 51,75 \\
MM $^{1}$ & 5,77 & 5,78 & 6,21 & 6,43 \\
MO $^{1}$ & 94,23 & 94,22 & 93,79 & 93,57 \\
PB $^{1}$ & 12,71 & 12,77 & 12,39 & 12,48 \\
NNP $^{2}$ & 29,81 & 30,28 & 29,44 & 30,39 \\
NIDN $^{2}$ & 18,91 & 17,68 & 17,89 & 18,08 \\
NIDA $^{2}$ & 11,01 & 10,97 & 10,90 & 10,94 \\
EE $^{1}$ & 3,30 & 2,63 & 2,62 & 2,51 \\
FDN $^{1}$ & 43,12 & 43,38 & 43,48 & 43,68 \\
FDN $_{\text {cp }}{ }^{1}$ & 40,28 & 40,82 & 40,92 & 41,06 \\
FDN $_{i}$ & 13,61 & 13,73 & 13,84 & 14,11 \\
CNF $^{1}$ & 38,66 & 38,71 & 38,58 & 38,24 \\
FDA $^{1}$ & 23,42 & 23,52 & 23,64 & 23,92 \\
Lignina $^{1}$ & 3,29 & 3,42 & 3,54 & 3,54 \\
NDT $^{1}$ & 64,85 & 63,10 & 63,59 & 62,18 \\
\hline I & & & &
\end{tabular}

$1 \%$ na matéria seca.

$2 \%$ do nitrogênio total.

${ }^{3}$ Níveis de resíduo de feijão nas dietas, na base da matéria seca (\%).

de leite. Para o cálculo da produção média de leite, foram considerados apenas os registros da última semana de cada período experimental. A produção de leite corrigida para 3,5\% de gordura (PLCg) foi calculada segundo Sklan et al. (1992), enquanto a produção de leite corrigida para 3,5\% de gordura e proteína (PLCgp), segundo Hall (2003).

A eficiência de alimentação foi calculada a partir das seguintes relações: eficiência de conversão alimentar (produção de leite corrigida para 3,5\% de gordura e proteína em função do consumo de MS) e eficiência protéica (kg de 
nitrogênio [N] lácteo em função do consumo de N), ambos propostos por Hall (2003); eficiência energética (Mcal de energia láctea, calculada segundo o NRC [2001], em função do consumo de NDT); e eficiência do manejo de concentrados (produção de leite em função da quantidade de concentrado ofertada).

Para determinação da composição do leite, duas amostras foram coletadas automaticamente no equipamento de ordenha, pela manhã e à tarde, no $11^{\circ} \underline{0}$ e $14^{\circ}$ dia de cada período experimental, perfazendo-se as amostras compostas em cada dia e acondicionadas conforme recomendações de Brito (2001). As análises dos teores de gordura (G), proteína bruta (PB), lactose (L), extrato seco total (EST) e extrato seco desengordurado (ESD) foram feitas no Laboratório de Qualidade do Leite, da Embrapa-CNPGL, em Juiz de Fora - MG.

No nono e décimo quinto dia de cada período experimental, os animais foram pesados para o monitoramento da variação de peso vivo (VPV). Esta variável foi utilizada apenas para compor o estudo, não tendo sido avaliada estatisticamente para efeito de discussão de resultados.

A digestibilidade da MS e dos demais nutrientes foi determinada pela utilização da fibra em detergente neutro indigestível (FDNi) como indicador interno, a qual foi determinada pela incubação in situ dos alimentos, sobras e fezes, durante um período de 144 horas, segundo técnica descrita por Cochran et al. (1986). As coletas de amostras fecais foram feitas diretamente no reto dos animais, duas vezes ao dia, após as ordenhas, durante os cinco primeiros dias dos períodos de coleta. Ao final de cada período, as amostras foram pré-secas (Silva \& Queiroz, 2002), formando uma amostra composta por animal e período.

O experimento foi analisado segundo delineamento em quadrado latino $4 \times 4$, sendo os animais agrupados em três diferentes quadrados segundo a dimensão do período decorrido após o parto. Posteriormente à análise de variância, procedeu-se à decomposição da soma de quadrados de tratamentos por intermédio de contrastes ortogonais relativos aos efeitos de ordens linear, quadrática e cúbica (Steel et al., 1997), em função dos níveis de inclusão do resíduo de feijão nos concentrados, com posterior ajuste de equações de regressão linear. Para todos os procedimentos estatísticos, adotou-se 0,05 como nível crítico de probabilidade para o erro tipo I.

\section{Resultados e Discussão}

As ingestões de MS, MO e dos nutrientes $\mathrm{PB}, \mathrm{EE}, \mathrm{CNF}$ e NDT diminuíram $(\mathrm{P}<0,05)$ com o aumento dos níveis de resíduo de feijão no concentrado, enquanto os consumos de FDN e FDNi, quando expressos em kg/dia, não foram afetados (Tabela 4). Os pequenos aumentos nos teores destes dois constituintes nas dietas com maiores níveis de resíduo podem explicar estes resultados.

A redução do consumo de MS pode ser atribuída a dois fatores: baixa palatabilidade do resíduo de feijão, conseqüência da presença de taninos no resíduo de feijão, e aumento da pulverulência dos concentrados, uma vez que, ao entrar em contato com a saliva dos animais, observou-se a formação de um material pastoso que dificultou a deglutição do bolo alimentar.

Segundo Mertens (1994), a relação FDN e enchimento é oposta à relação FDN e energia disponível. Então, a relação entre FDN e consumo será diferente, dependendo se o impedimento do consumo ou a demanda de energia limita o consumo em uma situação particular, ou seja, quando o enchimento limitar o consumo, este será negativamente correlacionado à concentração de FDN da dieta.

Por intermédio de análises de regressão de dados obtidos de 114 experimentos de digestibilidade, com vacas em lactação, Conrad et al. (1964) demonstraram que os fatores físicos e fisiológicos reguladores da ingestão de alimentos são alterados em importância com o aumento da digestibilidade da MS da dieta e que, para dietas abaixo de $66 \%$ de digestibilidade aparente, os fatores físicos foram determinantes do apetite.

Quando expresso em g/kg PV, o consumo de FDN apresentou redução linear $(\mathrm{P}<0,05)$ com o aumento dos níveis de resíduo nos concentrados. Entretanto, o mesmo não aconteceu com o consumo de $\mathrm{FDNi}$, o que pode ser indicativo de que o feijão retarda a degradação da FDN, ampliando o efeito de repleção ruminal associado à fração potencialmente degradável da FDN. Esta repleção poderia ser parcialmente explicada pelo aumento da digestão dos CNF, mais especificamente pela maior digestão do amido do resíduo de feijão no rúmen, elevando o tempo de colonização (lag time) da porção fibrosa (Mertens \& Loften, 1980). No entanto, a redução do consumo de CNF, associada à menor participação do amido como constituinte destes CNF, torna esta hipótese pouco provável.

A partir da tabela de requerimentos de consumo de MS do NRC (2001), estimou-se o valor de 34 g/kg PV para animais com $560 \mathrm{~kg}$ PV e PLCg para $4 \%$ de gordura de $22 \mathrm{~kg}$. Neste trabalho, os animais com $560 \mathrm{~kg}$ PV apresentaram PLCg para 4\% de 21,8; 22,3; 21,4 e 20,8 kg/dia. Dessa forma, todas as dietas foram ingeridas aquém da quantidade proposta, possível conseqüência da baixa qualidade da silagem de milho utilizada. Os níveis de ingestão de proteína e NDT observados atenderam ou foram ligeiramente inferiores às exigências propostas pelo NRC (2001), conforme pode ser observado na Tabela 5. Mesmo assim, os animais apre- 
Tabela 4 - Médias para os consumos diários de nutrientes da dieta, em função dos níveis de resíduo de feijão no concentrado

\begin{tabular}{|c|c|c|c|c|c|c|c|c|}
\hline \multirow[b]{2}{*}{ Item } & \multicolumn{4}{|c|}{ Nível de resíduo de feijão } & \multirow[t]{2}{*}{ CV (\%) } & \multicolumn{3}{|c|}{ Valor-P ${ }^{1}$} \\
\hline & 0 & 13 & 26 & 39 & & $\mathrm{~L}$ & Q & $\mathrm{C}$ \\
\hline & & & & & $\mathrm{kg} / \mathrm{dia}$ & & & \\
\hline $\mathrm{CMS}^{2}$ & 17,38 & 17,17 & 16,62 & 16,61 & 4,1 & 0,0049 & 0,6078 & 0,3350 \\
\hline $\mathrm{CMO}^{3}$ & 16,37 & 16,18 & 15,58 & 15,54 & 4,1 & 0,0016 & 0,6723 & 0,2652 \\
\hline $\mathrm{CPB}^{4}$ & 2,29 & 2,28 & 2,13 & 2,14 & 4,0 & $<0,0001$ & 0,7630 & 0,0181 \\
\hline$C E E^{5}$ & 0,61 & 0,48 & 0,46 & 0,44 & 5,2 & $<0,0001$ & $<0,0001$ & 0,0028 \\
\hline CFDN & 7,13 & 7,07 & 6,89 & 6,95 & 4,6 & 0,0977 & 0,5224 & 0,3993 \\
\hline CFDNi & 2,17 & 2,16 & 2,10 & 2,17 & 5,8 & 0,7906 & 0,2709 & 0,2567 \\
\hline $\mathrm{CCNF}^{6}$ & 6,34 & 6,35 & 6,10 & 6,01 & 3,8 & 0,0007 & 0,4882 & 0,2014 \\
\hline \multirow[t]{2}{*}{$\mathrm{CNDT}^{7}$} & 11,26 & 10,82 & 10,57 & 10,30 & 5,5 & 0,0007 & 0,6309 & 0,7749 \\
\hline & & & & & $\mathrm{g} / \mathrm{kg} \mathrm{PV}$ & & & \\
\hline $\mathrm{CMS}^{8}$ & 30,7 & 30,4 & 29,3 & 29,2 & 3,4 & 0,0004 & 0,6425 & 0,2061 \\
\hline $\mathrm{CFDN}^{9}$ & 12,62 & 12,50 & 12,16 & 12,23 & 3,8 & 0,0221 & 0,5069 & 0,3093 \\
\hline CFDNi & 3,84 & 3,82 & 3,71 & 3,83 & 5,0 & 0,5213 & 0,2401 & 0,1960 \\
\hline $\mathrm{CNDT}^{10}$ & 19,96 & 19,19 & 18,69 & 18,18 & 5,0 & 0,0001 & 0,6404 & 0,8236 \\
\hline
\end{tabular}

${ }^{1} \mathrm{~L}$, Q e C: efeitos de ordem linear, quadrática e cúbica, respectivamente.

${ }^{2} \hat{Y}=17,37-0,022 X\left(r^{2}=0,89\right) ;{ }^{3} \hat{Y}=16,38-0,0239 X\left(r^{2}=0,90\right) ;{ }^{4} \hat{Y}=2,29+0,0125 X-0,0013 X X^{2}+0,00002282 X^{3}\left(R^{2}=1,00\right) ;{ }^{5} \hat{Y}=0,61-0,0177 X+0,0006829 X^{2}-$ $0,00000866 X^{3}\left(R^{2}=1,00\right) ;{ }^{6} \hat{Y}=6,39-0,0096 X\left(r^{2}=0,88\right) ;{ }^{7} \hat{Y}=11,21-0,0242 X\left(r^{2}=0,98\right) ;{ }^{8} \hat{Y}=30,78-0,0433 X\left(r^{2}=0,90\right) ;{ }^{9} \hat{Y}=12,6-0,0117 X$ $\left(r^{2}=0,80\right) ;{ }^{10} \hat{Y}=19,88-0,0448 X\left(r^{2}=0,99\right)$.

Tabela 5 - Exigências nutricionais de PB e NDT preditas pelo NRC (2001) para vacas com $560 \mathrm{~kg}$ PV produzindo diariamente $22 \mathrm{~kg}$ de leite com 4\% de gordura (PLCg), PLCg observadas, estimativas dos consumos médios diários de PB e NDT e diferenças entre valores preditos e observados, expressos em $\mathrm{kg} / \mathrm{dia}$

\begin{tabular}{|c|c|c|c|c|c|c|c|}
\hline \multirow[t]{2}{*}{ Dieta } & \multirow[t]{2}{*}{ PLCg 4\% } & \multicolumn{2}{|c|}{ Exigência } & \multicolumn{2}{|c|}{ Consumo } & \multicolumn{2}{|c|}{ Diferença } \\
\hline & & PB & NDT & PB & NDT & PB & NDT \\
\hline 0 & 21,78 & 2,27 & 11,18 & 2,29 & 11,26 & $+0,02$ & $+0,08$ \\
\hline 13 & 22,25 & 2,27 & 11,18 & 2,28 & 10,82 & $+0,01$ & - 0,36 \\
\hline 26 & 21,35 & 2,27 & 11,18 & 2,13 & 10,57 & - 0,14 & - 0,61 \\
\hline 39 & 20,82 & 2,27 & 11,18 & 2,14 & 10,30 & $-0,13$ & $-0,88$ \\
\hline
\end{tabular}

sentaram VPV médias de 0,39; 0,26; 0,65 e 0,10 kg/dia, para os níveis crescentes de resíduo de feijão nas dietas, respectivamente.

As digestibilidades de MS, MO, EE e FDN não foram alteradas pela inclusão do resíduo de feijão nas dietas. A redução linear do CDPB $(\mathrm{P}<0,05)$ foi compensada pelo aumento linear do CDCNF $(\mathrm{P}<0,05)$, resultando na ausência de efeito para os CDMS e CDMO (Tabela 6).

A redução da digestibilidade da proteína deveu-se à substituição da proteína do farelo de soja pela proteína do feijão e pode ter concorrido para o aumento na repleção ruminal da FDN potencialmente digestível. Embora tenha ocorrido a substituição entre duas fontes leguminosas, o farelo de soja é um subproduto processado termicamente para obtenção do óleo, o que melhora suas características nutritivas enquanto fonte protéica. O valor nutritivo, especialmente protéico, de leguminosas aumenta com a aplicação de tratamento térmico, uma vez que causa desnaturação e diminui a solubilidade e a taxa de degradação protéica, favorecendo o escape de proteína dietética não-degradável no rúmen, além de promover melhor utilização dos peptídeos, isoácidos e amônia para a síntese de proteína microbiana em nível de rúmen (Van Soest, 1994).

Segundo Mendonça et al. (2003), a baixa digestibilidade da proteína do feijão é um dos seus problemas nutricionais. As globulinas e albuminas representam, em média, 75\% das proteínas do feijão (Lajolo et al., 1996), sendo que a globulina $\mathrm{G}_{1}$ especificamente, representa de 35 a $50 \%$ das proteínas totais. Uma das características das globulinas do feijão e da globulina $G_{1}$, em particular, é a resistência à proteólise quando não desnaturada, o que faz com que as proteínas do feijão apresentem digestibilidade inferior à de cereais e à de algumas leguminosas (Sgarbieri, 1996).

Outro fator prejudicial à digestibilidade protéica foi a presença de taninos, que em leguminosas são os polifenóis de maior importância, uma vez que os mesmos apresentam influência sobre a digestibilidade protéica. Os taninos do feijão possuem a capacidade de formar complexos com a 
Tabela 6 - Médias e coeficientes de digestibilidade aparente dos nutrientes da dieta, em função dos níveis de resíduo de feijão no concentrado

\begin{tabular}{|c|c|c|c|c|c|c|c|c|}
\hline Item & \multicolumn{4}{|c|}{ Nível de resíduo de feijão } & CV (\%) & \multicolumn{3}{|c|}{ Valor $\mathrm{P}^{1}$} \\
\hline CDMS & 63,45 & 62,13 & 63,02 & 61,67 & 3,7 & 0,1541 & 0,9848 & 0,1542 \\
\hline CDMO & 64,99 & 64,03 & 64,86 & 63,67 & 3,4 & 0,2865 & 0,8546 & 0,1963 \\
\hline $\mathrm{CDPB}^{2}$ & 61,20 & 60,21 & 57,73 & 55,50 & 5,0 & $<0,0001$ & 0,4685 & 0,6481 \\
\hline CDEE & 82,91 & 79,89 & 81,28 & 79,15 & 4,7 & 0,0586 & 0,6889 & 0,1229 \\
\hline CDFDN & 44,52 & 43,19 & 45,08 & 42,39 & 6,9 & 0,2650 & 0,4471 & 0,0607 \\
\hline
\end{tabular}

${ }^{1} \mathrm{~L}, \mathrm{Q}$ e C: efeitos de ordem linear, quadrática e cúbica, respectivamente; ${ }^{2} \hat{\mathrm{Y}}=61,60-0,1506 \mathrm{X}\left(\mathrm{r}^{2}=0,97\right) ;{ }^{3} \hat{\mathrm{Y}}=87,05+0,0655 \mathrm{X}\left(\mathrm{r}^{2}=0,82\right)$.

globulina $\mathrm{G}_{1}$, basicamente por meio de interações hidrofóbicas, produzindo diminuição significativa na digestibilidade dessa fração, mesmo em concentrações elevadas de proteases (Lajolo et al., 1996).

Embora os taninos não tenham sido quantificados no resíduo de feijão, indiretamente no laboratório, pode-se observar sua presença, quando do tratamento do resíduo para determinação da FDA, resultando na coloração rósea intensa da solução detergente. A formação de grupos oxônios é catalisada por ácido, sendo a coloração vermelha ou rósea da solução indicativo da presença de taninos condensados (Van Soest, 1994).

O aumento da digestibilidade dos CNF $(\mathrm{P}<0,05)$ pode ser conseqüência da substituição parcial do fubá de milho pelo resíduo de feijão. $\mathrm{O}$ amido representou a maioria dos CNF do milho, enquanto, no resíduo de feijão, o amido representou cerca de 60\% dos CNF (Tabela 2), ou seja, houve uma mudança nos constituintes dessa fração de carboidratos. Outra possível causa foi a maior pulverulência observada nos concentrados com o aumento dos níveis de resíduo, o que propiciou maior superfície específica das partículas para hidratação e posterior degradação pelos microrganismos ruminais.

A produção corrigida ou não e a composição do leite, quando expressas em $\mathrm{kg} /$ dia, diminuíram linearmente com a inclusão do resíduo de feijão nas dietas $(\mathrm{P}<0,05)$ (Tabela 7). Tais reduções foram conseqüências diretas da diminuição da ingestão de MS e de nutrientes dietéticos, o que limitou o aporte de nutrientes para a glândula mamária.

Pereira et al. (2005), trabalhando com diferentes níveis de PB (11,3 a 14,4\%) nas dietas à base de silagem de milho e concentrados, para vacas em lactação com produções médias diárias de $19 \mathrm{~kg}$ de leite, concluíram que o nível 12,3\% de PB foi o que resultou em maior produção de leite. Então, o nível médio de $12,6 \%$ de PB obtido neste estudo não foi o fator determinante para a produção de leite, mas sim a ingestão de MS.
Dos três componentes lácteos avaliados, a lactose foi o único a apresentar diferença $(\mathrm{P}<0,05)$, quando expressa em \% e kg/dia, o que, conseqüentemente, concorreu para o mesmo comportamento do ESD. A lactose é o componente do leite que apresenta concentração mais estável, sendo essencialmente uma constante de 4,85\% do leite (NRC, 2001). Oba \& Allen (1999), ao avaliarem dados compilados da literatura acerca da variação da digestibilidade da FDN, observaram que o teor de lactose tendeu a ser maior para tratamentos com digestibilidades mais elevadas de FDN. O BBSRC (1998) apresentou sumário dos principais efeitos do suprimento de produtos finais da digestão sobre os constituintes do leite, no qual indica que a redução do acetato acarreta diminuição no teor de lactose do leite. Então, um possível estreitamento da relação acetato: propionato no rúmen, em conseqüência da elevação da digestão dos CNF e da baixa digestibilidade da FDN das dietas, pode ser a causa dos teores de lactose observados neste estudo. Contudo, os níveis de acetato foram adequados para a manutenção dos teores de gordura do leite. As reduções lineares $(P<0,05)$ das produções de $G$, PB e EST, em kg/dia, decorreram exclusivamente da diminuição da produção de leite.

As eficiências não foram afetadas pelos níveis de resíduo de feijão nos concentrados (Tabela 8).

A eficiência de conversão alimentar obtida pode ser considerada satisfatória, uma vez que valores da ordem de 1,3 a 1,5 encontram-se dentro de um padrão de normalidade (Hutjens, 2002). Valores abaixo de 1,3 indicam baixa eficiência, o que pode ser obtido em rebanhos com baixo potencial de produção de leite ou submetidos a estresse, em vacas primíparas, vacas em final de lactação e/ou gestação e ainda alimentadas com volumosos de baixa qualidade. Por outro lado, eficiências superiores a 1,5 são excelentes e podem ser reflexo de alto potencial de produção, elevada mobilização de reservas corporais (animais em início de lactação) ou o fornecimento de volumosos de alta qualidade (Hutjens, 2004). 
Tabela 7 - Médias para produção de leite (PL), produção de leite corrigida para 3,5\% de gordura (PLCg) e 3,5\% de gordura e proteína (PLCgp) e teores de gordura (G), proteína bruta (PB), lactose (L), extrato seco total (EST) e extrato seco desengordurado (ESD), em função dos níveis de resíduo de feijão no concentrado

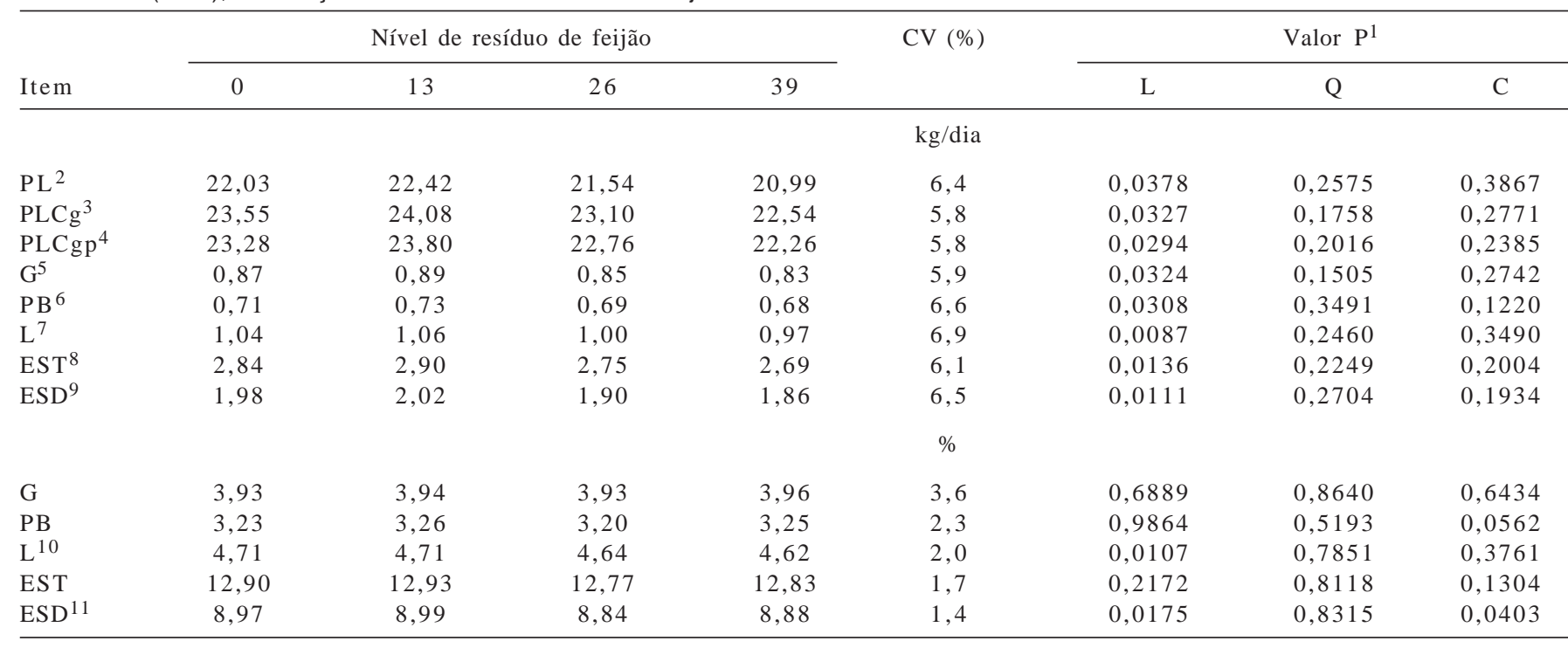

${ }^{1} \mathrm{~L}$, Q e C: efeitos de ordem linear, quadrática e cúbica, respectivamente.

$2 \hat{Y}=22,35-0,0308 X\left(r^{2}=0,70\right) ;{ }^{3} \hat{Y}=23,92-0,0308 X\left(r^{2}=0,62\right) ;{ }^{4} \hat{Y}=23,64-0,0315 X\left(r^{2}=0,63\right) ;{ }^{5} \hat{Y}=0,88-0,0012 X\left(r^{2}=0,60\right) ;{ }^{6} \hat{Y}=0,72-0,0011 X\left(r^{2}=0,60\right) ;$ ${ }^{7} \hat{\mathrm{Y}} 1,06-0,0020 \mathrm{X}\left(\mathrm{r}^{2}=0,78\right) ;{ }^{8} \hat{\mathrm{Y}}=2,89-0,0046 \mathrm{X}\left(\mathrm{r}^{2}=0,69\right) ;{ }^{9} \hat{\mathrm{Y}}=2,01-0,0035 \mathrm{X}\left(\mathrm{r}^{2}=0,72\right) ;{ }^{10} \hat{\mathrm{Y}}=4,72-0,0027 \mathrm{X}\left(\mathrm{r}^{2}=0,90\right) ;{ }^{11} \hat{\mathrm{Y}}=8,98-0,0033 \mathrm{X}\left(\mathrm{r}^{2}=0,58\right)$

Tabela 8 - Médias e níveis descritivos de probabilidade (Valor-P) para a eficiência de conversão alimentar (ECA), eficiência protéica $(E P)$, eficiência energética (EE) e do manejo de concentrados (EMC), em função dos níveis de resíduo de feijão no concentrado

\begin{tabular}{|c|c|c|c|c|c|c|c|c|}
\hline Item & \multicolumn{4}{|c|}{ Nível de resíduo de feijão } & CV (\%) & \multicolumn{3}{|c|}{ Valor $\mathrm{P}^{1}$} \\
\hline ECA & 1,34 & 1,38 & 1,37 & 1,34 & 6,9 & 0,7853 & 0,2435 & 0,7336 \\
\hline $\mathrm{EE}$ & 1,43 & 1,51 & 1,47 & 1,48 & 7,7 & 0,4764 & 0,2591 & 0,2694 \\
\hline EMC & 2,48 & 2,45 & 2,48 & 2,40 & 7,3 & 0,3902 & 0,6257 & 0,4790 \\
\hline
\end{tabular}

${ }^{1}$ L, Q e C: efeitos de ordens linear, quadrática e cúbica, respectivamente.

Segundo o NRC (2001), as pesquisas com vacas em lactação têm sido direcionadas para a melhoria da eficiência de utilização da proteína e do nitrogênio dietético. Dessa forma, as rações de vacas em lactação devem ser formuladas para otimizar o conteúdo de PB tanto para produção de leite quanto para a eficiência de utilização do $\mathrm{N}$, sendo esta afetada por diversos fatores relacionados aos animais, alimentos e dietas. Segundo Chase (2003), tipos, quantidades e degradabilidades dos carboidratos e das fontes de $\mathrm{N}$ dietéticos são determinantes dessa eficiência.

Neste trabalho, os animais alcançaram a eficiência protéica de 0,30 proposta por Hall (2003) e eficiência energética em torno de 1,45. A utilização de proteína e energia depende amplamente da fermentação no rúmen. A extensão e o tipo de fermentação determinam a natureza e as quantidades dos vários metabólitos que serão absorvidos a partir do trato gastrintestinal, os quais afetam a eficiência de produção de leite e a forma de utilização da energia (síntese de leite versus formação de tecidos corporais) (NRC, 1989). Dessa forma, pode-se inferir que houve ingestão balanceada de proteína e carboidratos fermentescíveis dietéticos para utilização pelos microrganismos ruminais. Pereira et al. (2005), trabalhando com diferentes níveis de PB (11,3 a 14,4\%) em dietas para vacas em lactação, encontraram eficiência de utilização de $\mathrm{N}$ de 0,308. Esses autores sugeriram que níveis de PB superiores podem ter ocasionado excedente de PDR. Vários autores têm obtido valores mais elevados nessa eficiência quando os níveis de PB dietéticos são menores (Kalscheur et al., 1999; Wu \& Satter, 2000; Broderick, 2003).

A eficiência de manejo de concentrados obtida não correspondeu às recomendações práticas de $1 \mathrm{~kg}$ de concentrado para cada 2,5 a $3 \mathrm{~kg}$ de leite produzidos. Deve-se ressaltar que, para que o cálculo dessa eficiência tenha 
relevância prática, torna-se necessária a uniformidade das sobras entre os tratamentos, que foram de 10,$4 ; 11,5 ; 10,9$ e 11,5\% da quantidade diária de MS de ração total ofertada, para os níveis crescentes de resíduo de feijão nas dietas, respectivamente. Diante de todos os índices de eficiência obtidos, conclui-se que a baixa qualidade da silagem de milho utilizada (Tabela 2) talvez tenha respondido como maior obstáculo à obtenção de melhores resultados, visto que a qualidade do volumoso é de suma importância na alimentação de vacas leiteiras.

\section{Conclusões}

A inclusão de resíduo de feijão em rações completas à base de concentrado e silagem de milho, para vacas com produções médias diárias de $22 \mathrm{~kg}$ de leite, implica em redução na produção de leite, embora não comprometa a eficiência de utilização dos alimentos. Sugere-se que sejam desenvolvidos trabalhos no sentido de estabelecer os níveis de inclusão de resíduo de feijão em rações para vacas leiteiras em lactação.

\section{Literatura Citada}

ASSOCIATION OF OFFICIAL ANALYTICAL CHEMISTS - AOAC. Official methods of analysis. 16.ed. Washington, D.C.: 1995. 2000p.

BIOTECHNOLOGY AND BIOLOGICAL SCIENCES RESEARCH COUNCIL - BBSRC. Responses in the yield of milk constituents to the intake of nutrients by dairy cows. New York: CABI Publishing, 1998. 96p.

BRITO, J.R.F. Coleta de amostras de leite para determinação da composição química e contagem de células somáticas. Juiz de Fora: Embrapa - CNPGL, 2001. p.16. (Circular Técnica, 62).

BRODERICK, G.A. Effects of varying dietary protein and energy levels on the production of lactating dairy cows. Journal of Dairy Science, v.86, n.4, p.1370-1381, 2003.

CHASE, L.E. Nitrogen utilization in dairy cows - what are the limits of efficiency? In: CORNELL NUTRITION CONFERENCE FOR FEED MANUfACTURERS, 65., 2003, Ithaca. Proceedings... Ithaca: Cornell University, 2003. p.233-244.

COCHRAN, R.C.; ADAMS, D.C.; WALLACE, J.D. et al. Predicting digestibility of different diets with internal markers: Evaluation of four potential markers. Journal of Animal Science, v.63, n.5, p.1476-1483, 1986.

COMPANHIA NACIONAL DE ABASTECIMENTO - CONAB. [2005]. Série histórica de produção de feijão - Brasil. Disponível em: http://www.conab.gov.br>. Acesso em: 21/1/ 2005.

CONRAD, H.R.; PRATT, A.D.; HIBBS, J.W. Regulation of feed intake in dairy cows. 1. Change in importance of physical and physiological factors with increasing digestibility. Journal of Dairy Science, v.47, n.1, p.54-62, 1964.

DEPARTMENT OF PRIMARY INDUSTRIES AND FISHERIES DPI. [2003]. Navy beans for stockfeed. Disponível em: http:/ /<www.dpi.qld.gov.au> Acesso em: 9/4/2003.

FERREIRA, A.M.; TORRES, C.A.A. Perda de peso corporal e cessação da atividade ovariana luteínica cíclica em vacas mestiças leiteiras. Pesquisa Agropecuária Brasileira, v.28, n.3, p.411-418, 1993.

HALL, M.B. Neutral detergent-soluble carbohydrates: nutritional relevance and analysis, a laboratory manual. Gainesville: University of Florida, 2000. (Extension Bulletin, 339). 42p.

HALL, M.B. What you feed vs. what you get: feed efficiency as an evaluation tool. In: ANNUAL FLORIDA RUMINANT NUTRITION SYMPOSIUM, 14., 2003, Gainesville. Anais eletrônico... Gainsville, 2003. p.25-31. Disponível em: <www.traill. uiuc.edu> Acesso em: 2/2/2005

HUTJENS, M.F. Using dairy efficiency. [2002]. Disponível em: $<$ www.traill.uiuc.edu>. Acesso em: 2/2/2005.

HUTJENS, M.F. Enhancing profitability through setting strategic feed efficiency targets. In: WESTERN CANADIAN DAIRY SEMINAR - Advances in Dairy Technology, 2004, Edmonton. Proceedings... Edmonton: University of Alberta, 2004. v.16, p.23-27.

KALSCHEUR, K.F.; VANDERSALL, J.H.; ERDMAN, R.A. et al. Effects of dietary crude protein concentration and degradability on milk production responses of early, mid and late lactation dairy cows. Journal of Dairy Science, v.82, n.2, p.545-554, 1999.

LAJOLO, F.M.; GENOVESE, M.I.; MENEZES, E.W. Qualidade Nutricional. In: ARAÚJO, R.S.; RAVA, C.A.; STONE, J.F. et al. (Eds.) Cultura do feijoeiro comum no Brasil. Piracicaba: POTAFÓS, 1996. p.23-56.

LICITRA, G.; HERNANDEZ, T.M.; van SOEST, P.J. Standardization of procedures for nitrogen fractionation of ruminant feeds. Animal Feed Science and Technology, v.57, p.347-358, 1996.

MENDONÇA, C.V.C.E.; ABREU, C.M.P.; CORRÊA, A.D. et al. Quantificação de polifenóis e digestibilidade protéica de famílias de feijoeiro comum. Ciência e Agrotecnologia, v.27, n.4, p.858-864, 2003.

MERTENS, D.R. Regulation of forage intake. In: FAHEY JR., G.C. (Ed.) Forage quality, evaluation, and utilization. Wisconsin: 1994. p.450-493.

MERTENS, D.R.; LOFTEN, J. R. The effect of starch on forage fiber digestion kinetics in vitro. Journal of Dairy Science, v.63, n.9, p.1437-1446, 1980.

MOSS, R. [2005]. Can legume grains be used for dairy cows? Disponível em: <www.dpi.qld.gov.au>. Acesso em: 3/2/2005.

NATIONAL RESEARCH COUNCIL - NRC. Nutrient requirements of dairy cattle. 6.ed. Washington, D.C: National Academic Press, 1989. 158p.

NATIONAL RESEARCH COUNCIL - NRC. Nutrient requirements of dairy cattle. 7.ed. Washington, D.C: National Academic Press, 2001. 381p.

NUNES, I.J. Cálculo e avaliação de rações e suplementos. Belo Horizonte: FEP-MVZ, 1998. 185p.

OBA, M.; ALLEN, M.S. Evaluation of the importance of the digestibility of neutral detergent fiber from forage: effects on dry matter intake and milk yield of dairy cows. Journal of Dairy Science, v.82, n.3, p.589-596, 1999.

PEREIRA, J.C. Vacas leiteiras - aspectos práticos da alimentação. Viçosa, MG: Editora Aprenda Fácil, 2000. 198p.

PEREIRA, M.L.A.; VALADARES FILHO, S.C.; VALADARES, R. F.D. et al. Consumo, digestibilidade aparente total, produção e composição do leite em vacas no terço médio da lactação alimentadas com níveis crescentes de proteína bruta no concentrado. Revista Brasileira de Zootecnia, v.34, n.3, p.1040-1050, 2005.

SGARBIERI, V.C. Proteínas em alimentos protéicos: propriedades, degradações, modificações. São Paulo: Livraria Varela, 1996. $517 p$.

SILVA, D.J.; QUEIROZ, A.C. Análise de alimentos (Métodos químicos e biológicos). 3.ed. Viçosa, MG: Editora UFV, 2002. $235 p$. 
SINDICATO NACIONAL DA INDÚSTRIA DE ALIMENTAÇÃO ANIMAL - SINDIRAÇÕES. Compêndio brasileiro de alimentação animal. São Paulo: 1998. 371p.

SKLAN, D.; ASHKENAZI, R.; BRAUN, A. et al. Fatty acids, calcium soaps of fatty acids, and cottonseeds fed to high yielding cows. Journal of Dairy Science, v.75, n.9, p.2463-2472, 1992.

SteEL, R.G.D.; TORRIE, J.H.; DICKeY, D.A. Principles and procedures of statistics: a biometrical approach. 3.ed. New York: McGraw-Hill, 1997. 666p.

Van SOEST, P.J. Nutritional ecology of the ruminant. 2.ed. Ithaca: Cornell University Press, 1994. 476p.
WALTER, M.; SILVA, L.P.; PERDOMO, D.M.X. Amido disponível e resistente em alimentos: adaptação do método da AOAC 996.11. Alimentos e Nutrição, v.16, n.1, p.39-43, 2005.

WEISS, W.P. Energy prediction equations for ruminant feeds. In: CORNELL NUTRITION CONFERENCE FOR FEED MANUFACTURERS, 61., 1999, Proceedings... Ithaca: Cornell University, 1999. p.176-185.

WU, Z.; SATTER, L.D. Milk production during the complete lactation of dairy cows fed diets containing different amount of protein. Journal of Dairy Science, v.83, n.3, p.10421051, 2000. 